\title{
SUPERVISI AKADEMIK INTERNAL GURU TK PENDEKATAN KOLABORATIF
}

\author{
Libri Rizka Puri Windarta \\ IAIN Syekh Nurjati Cirebon \\ Email: libririzka@iainsyekhnurjati.ac.id
}

\begin{abstract}
The principals have their own authority to carry out internal supervision and choose the type of approach used in schools according to the characteristics of the institution. The benefits of internal academic supervision are to improve teacher professional competence and teacher techniques in the learning process. The research was conducted at $A B A$ Sumberadi Kindergarten which has 7 teachers, conducted in December. The purpose of this research is to get a real picture of institutions that use a collaborative approach in academic supervision. This type of research is qualitative, research subjects are principals and teachers. Techniques for collecting interview data and documents, interviews were conducted directly by the principal and teachers by meeting at school. The research data analysis technique used descriptive qualitative analysis techniques by analyzing the data obtained from interviews and then processed and presented with narration. The findings of this study are the collaborative approach is the approach chosen by schools because it is considered more effective for institutional improvement and principals are more flexible in exploring obstacles that arise in the learning process.
\end{abstract}

Key words: Supervision academic; kindergarten teacher; collaboration

\begin{abstract}
Abstrak: Kepala sekolah mempunyai kewenangan sendiri untuk melakukan supervisi internal dan memilih jenis pendekatan yang digunakan di sekolah sesuai dengan karakteristik lembaga, Manfaat supervisi akademik internal adalah untuk meningkatkan kompetensi profesionalitas guru dan teknik guru dalam proses pembelajaran. Penelitian dilakukan di TK ABA Sumberadi yang memiliki jumlah guru 7 orang,dilakukan pada bulan Desember. Tujuan penelitian untuk memperoleh gambaran nyata tentang lembaga yang menggunakan pendekatan kolaboratif dalam supervisi akademik. Jenis penelitiannya kualitatif, subyek penelitian kepala sekolah dan guru. Teknik pengumpulan data wawancara dan dokumen, wawancara dilakukan secara langsung oleh kepala sekolah dan guru dengan bertemu di sekolah. Teknik analisis data penelitian menggunakan teknik analisis deskriptif kualitatif dengan cara menganalisis data yang di dapat dari wawancara kemudian diolah dan disajikan dengan narasi. Temuan penelitian ini adalah pendekatan kolaborasi merupakan pendekatan yang dipilih oleh kepada sekolah karena dipandang lebih efektif untuk perbaikan lembaga dan kepala sekolah lebih leluasa dalam menggali kendala yang muncul pada proses pembelajaran.
\end{abstract}

Kata kunci: Supervisi akademik ; guru TK ; kolaborasi 
Libri Rizka P.W., Supervisi Akademik Internal Guru TK Pendekatan

Kolaboratif

\section{PENDAHULUAN}

Kemajuan suatu lembaga ditentukan oleh beberapa faktor, diantaranya adalah faktor guru dan kepala sekolah. Guru serta kepala sekolah harus memiliki kompetensi dan profesionalitas di bidangnya. Menurut Permendikbud No. 137 Tahun 2014 pasal 29 ayat 1 dan 2 semestinya memiliki kualifikasi akademik sebagai kepala $\mathrm{KB} / \mathrm{TK}$ dan memiliki kompetensi kepala lembaga PAUD salah satu kompetensi yang perlu dimiliki adalah supervisi. Supervisi yang dijalankan oleh seorang kepala sekolah yaitu supervisi akademik terhadap guru TK dalam manajemen pembelajaran. Artinya, kepala sekolah harus mensupervisi pekerjaan yang dilakukan tenaga kependidikan dan tenaga pendidik dengan tujuan utama dari supervisi akademik adalah untuk meningkatkan dan mengembangkan kompetensi, memperbaiki atau meningkatkan metode pengajaran yang digunakan oleh guru sehingga guru tersebut layak dipandang sebagai guru ideal. Terutama bagi guru TK dengan latar belakang pendidikan bukan dari S1 pendidikan. ${ }^{1}$

Guru TK yang berasal dari lulusan non kependidikan biasanya mengalami hambatan dalam pengelolaan pembelajaran, karena butuh penyesuaian diri dan belum memahami cara membuat perencanaan pembelajaran bahkan tentang pelaksanaannya. Cara yang tepat untuk mengembangkan kemampuan tersebut adalah dengan melalui supervisi akademik internal yang dilakukan oleh kepala sekolah sehingga guru dapat mengetahui letak kekurangan pada saat mengajar. Kompetensi supervisi akademik kepala sekolah terdiri dari tiga aspek yaitu kompetensi dalam

\footnotetext{
1 Nini Aryani, M S Mudjiran, And M Pd Rakimahwati, Manajemen Pembelajaran Paud: Berbasis Perkembangan Anak (Edu Publisher, 2020).
} 
menyusun program, melaksanakan, mengevaluasi dan menindaklanjuti temuan-temuan pada saat proses pembelajaran. ${ }^{2}$

Supervisi mengandung beberapa beberapa kegiatan pokok, diantaranya pembinaan yang berkelanjutan, pengembangan kemampuan profesional guru, perbaikan situasi belajar mengajar dengan sasaran akhir pencapaian tujuan pendidikan dan pertumbuhan pribadi. ${ }^{3}$ Dalam kegiatan supervisi internal yang dilakukan oleh supervisor, yaitu kepala sekolah perlu memberikan bimbingan kepada guru agar apa yang diperolehnya diterapkan atau diaplikasikan dalam proses belajar mengajar yang dilakukannya. Bimbingan dan pengembangan ini antara lain dilakukan dengan cara kunjungan kelas, pertemuan pribadi, observasi dan diskusi. Kepala sekolah selaku supervisor dapat menggunakan satu pendekatan yang dapat digunakan dalam pelaksanaan ${ }^{4}$. Sebelumnya kepala sekolah menggunakan supervisi individual dalam melaksanakan tugas supervisi akademik dengan cara mendatangi guru yang sedang mengajar, mengamati cara kerjanya dan melakukan penilaian. Pendekatan supervisi individual yang dilakukan dipandang tidak terlalu efektif untuk meningkatkan kompetensi guru dalam melaksanakan tugasnya. Oleh karena itu kepala sekolah lebih memilih pendekatan kolaboratif dalam melaksanakan supervisi akademik internal di lembaganya.

Tujuan dari penelitian ini adalah untuk memperoleh gambaran nyata tentang lembaga yang menggunakan pendekatan kolaboratif dalam supervisi akademik yang dilakukan di TK ABA Sumberadi. Sedangkan manfaat praktis dalam penelitian ini adalah untuk meningkatkan kompetensi

\footnotetext{
2 Marike Simbolon, "Penerapan Pendekatan Supervisi Kolaboratif Untuk Meningkatkan Kompetensi Profesional Guru Di Sd Negeri 10 Lumban Suhisuhi Kecamatan Pangururan Kabupaten Samosir," Informasi Dan Teknologi IImiah (Inti) 6, No. 1 (2018): 108-13.

${ }^{3}$ Mulyawan Safwandy Nugraha, "Pelaksanaan Supervisi Akademik Oleh Kepala Madrasah Aliyah Swasta Di Kabupaten Sukabumi Jawa Barat," Nadwa 9, No. 1 (2014): 39-68.

${ }^{4}$ Hotnida Sihite, "Upaya Meningkatkan Kompetensi Profesional Guru Melalui Penerapan Pendekatan Supervisi Kolaboratif Bagi Guru Sd Negeri 157019 Pinangsori 12 Kecamatan Pinangsori Kab. Tapanuli Tengah Pada Semester Ganjil Tahun Pelajaran 2019/2020," Peteka 2, No. 2 (2019): 83-94.
} 
Libri Rizka P.W., Supervisi Akademik Internal Guru TK Pendekatan Kolaboratif

profesionalitas guru dan teknik guru dalam proses pembelajaran. Sedangkan bagi kepala sekolah adalah dapat meningkatkan atau memperbaiki pelaksanaan supervisi akademik, bagi guru dapat dirasakan manfaatnya yakni manajemen pembelajaran yang dilakukan guru dapat diketahui kekurangan dan kelebihannya sehingga memudahkan berkembang selalu terkait dengan proses belajar guru sendiri yang bersifat individual.

\section{METODE PENELITIAN}

Jenis penelitian ini menggunakan penelitian deskriptif kualitatif, penelitian dilakukan pada bulan Desember tahun 2020 di TK ABA Sumberadi, subyek penelitian ini adalah kepala sekolah dan guru TK ABA Sumberadi. Penelitian ini bertujuan untuk mendapatkan data atau gambaran yang secara objektif, faktual, akurat dan sistematis mengenai implementasi supervisi akademik internal dengan pendekatan kolaboratif bagi guru TK yang akan dikaji oleh peneliti.

Teknik pengumpulan data yang digunakan yaitu wawancara dan dokumen. Teknik analisis data dalam penelitian ini menggunakan teknik analisis deskripstif kualitatif, yaitu dengan cara mengumpulkan data yang didapat dari hasil wawancara dan penggalian dokumen yang dilakukan setelah itu, hasil data dianalisis dan diolah yang kemudian disajikan menggunakan narasi.

Wawancara merupakan salah satu teknik yang dapat digunakan untuk mengumpulkan data penelitian, secara sederhana dapat dikatakan bahwa wawancara adalah suatu kejadian atau suatu proses interaksi antara pewawancara dan sumber informasi atau orang yang diwawancarai. ${ }^{5}$

\footnotetext{
${ }^{5}$ A Muri Yusuf, Metode Penelitian Kuantitatif, Kualitatif \& Penelitian Gabungan (Prenada Media, 2016).
} 
Pewawancara adalah peneliti dan sumber informasi adalah responden. Wawancara yang dilakukan menggunakan wawancara terstruktur, dengan wawancara terstruktur ini peneliti memberi pertanyaan dengan pedoman wawancara yang disusun secara terperinci sehingga menyerupai checklist. kemudian pertanyaan tersebut diberikan sama kepada responden. Adapun responden yang diwawancarai adalah kepala sekolah, wakil sekolah dan guru-guru TK dengan maksud agar peneliti mendapat data supervisi akademik internal dengan pendekatan kompetensi yang dilakukan oleh supervisor yaitu kepala sekolah.

Kemudian untuk teknik pengumpulan data yang kedua adalah dokumentasi, di dalam melaksanakan metode dokumentasi peneliti menggali benda-benda tertulis seperti hasil wawancara berupa checklist, dokumen pendukung dan lainnya. ${ }^{6}$ Selain itu peneliti juga merekam wawancara yang dilakukan bersama responden yaitu kepala sekolah, wakil kepala sekolah dan guru TK.

\section{KERANGKA TEORI}

Supervisi dapat diartikan pengarahan, pengendalian yang dilakukan seorang pimpinan kepada bawahannya dalam lingkup organisasi dalam rangka pencapaian tujuan organisasi. ${ }^{7}$ Pada dasarnya supervisi dalam pembelajaran dilakukan pada dua aspek yaitu supervisi akademik dan supervisi manajerial. Supervisi akademik menitikberatkan pada pengamatan supervisor terhadap kegiatan akademik ${ }^{8}$ berupa pembelajaran sedangkan supervisi manajerial melihat pada aspek-aspek pengelolaan administrasi sekolah sebagai pendukung pembelajaran.

6 Iwan Hermawan, Metodologi Penelitian Pendidikan (Kualitatif, Kuantitatif Dan Mixed Method) (Hidayatul Quran, 2019).

7Jurnal

8 Awaluddin Sitorus And Siti Kholipah, M Pd Supervisi Pendidikan: Teori Dan Pengaplikasian (Swalova Publishing, 2018). 
Libri Rizka P.W., Supervisi Akademik Internal Guru TK Pendekatan Kolaboratif

Kegiatan supervisi dahulu banyak dilakukan adalah inspeksi, pemeriksaan, pengawasan, atau penilikan. Supervisi masih serumpun dengan pengawasan, pemeriksaan dan penilikan dalam arti kegiatan yang dilakukan oleh atasan terhadap yang berposisi di atas terhadap hal-hal yang ada di bawahnya. Pada hakikatnya supervisi adalah sebagai bantuan dan bimbingan profesional bagi guru dalam melaksanakan tugas instruksional guna memperbaiki hal belajar dan mengajar dengan melakukan stimulasi, koordinasi dan bimbingan secara kontinu.

Keinginan utama kepala sekolah dalam kegiatan pengawasannya dikosentrasikan pada peningkatan mutu pembelajaran yang terarah pada usaha membantu guru agar bisa keluar dari kesulitan mengajar yang dihadapinya dengan memperkaya kemampuan dan pengetahuan dalam menjalankan tugasnya. Keinginan para kepala sekolah ini bahwa guru merupakan penjamin kualitas pendidikan yang sebenarnya. ${ }^{9}$

Efektivitas pelaksanaan kinerja profesional guru sangat bergantung pada kompetensi kepala sekolah dalam melaksanakan tugasnya diantaranya dalam melakukan supervisi akademik. Untuk melaksanakan supervisi akademik, kepala sekolah sebagai supervisor dan penanggungjawab kegiatan di sekolah harus mampu menyusun program, melaksanakan dan melakukan tindak lanjut supervisi akademik di sekolah yang dipim[innya. Pelaksanaan supervisi yang baik oleh kepala sekolah akan menghasilkan kompetensi guru dalam memfasilitasi pembelajaran yang baik pula. Selanjutnya pembelajaran yang dilakukan secara baik akan membuat peserta didik menjadi nyaman dalam mengikuti proses pembelajaran, karena dalam pendidikan anak usia dini yang dilihat bukanlah hasil akhir melainkan proses perkembangan anak. Dengan demikian, keberhasilan perkembangan anak usia dini sangat bergantung

9 Simbolon, "Penerapan Pendekatan Supervisi Kolaboratif Untuk Meningkatkan Kompetensi Profesional Guru Di Sd Negeri 10 Lumban Suhisuhi Kecamatan Pangururan Kabupaten Samosir." 
dari kemampuan guru dalam memfasilitasi dan memberikan kegiatan yang dapat menstimulasi perkembangan anak serta kompetensi kepala sekolah dalam melaksanakan supervisi akademik. ${ }^{10}$ Supervisi akademik adalah aktivitas pembinaan melalui pemberian pertolongan teknis kepada guru dalam melaksanakan proses pembelajaran. Supervisi akademik ini dapat dilakukan dari eksternal (pengawas sekolah) dan internal (kepala sekolah). ${ }^{11}$

Menurut Alfonso dkk ada tiga konsep pokok dalam pengertian supervisi akademik, pertama : supervisi akademik harus secara langsung mempengaruhi dan mengembangkan perilaku guru dalam mengelola proses pembelajaran, kedua : perilaku supervisor dalam membantu guru mengembangkan kemampuannya harus didesain secara ofisial sehingga jelas waktu mulai dan berakhirnya program pengembangan tersebut. Terakhir tujuan akhir supervisi akademik adalah agar guru semakin mampu memfasilitasi belajar bagi murid-muridnya. ${ }^{12}$

Supervisi akademik pada prinsipnya untuk meningkatkan kualitas guru, menurut Musfah menyatakan bahwa proses supervisi akademik dapat dilakukan dengan berbagai macam pendekatan yaitu pendekatan humanistik, pendekatan kompetensi, pendekatan klinis dan pendekatan profesional $^{13}$. Sementara menurut Nolan merinci pendekatan supervisi menjadi tiga jenis yaitu Pendekatan Langsung (direktif), Pendekatan tidak langsung (Nondirektif) dan pendekatan kolaboratif. ${ }^{14}$ Untuk lembaga TK

10 Mutahajar Mutahajar, "Penerapan Supervisi Kolaboratif Untuk Meningkatkan Kompetensi Profesional Guru Sdn 6 Jurit Kecamatan Pringgasela," Bintang 1, No. 3 (2019): 282-303.

11 Desi Kusumawati, "Supervisi Akademik Kepala Sekolah Terhadap Manajemen Pembelajaran Paud," Satya Widya 32, No. 1 (2016): 41-48.

12 Nana Mulyana, Modul Pengembangan Kemampuan Supervisi Akademik Bagi Kepala Sekolah (Edu Publisher, 2019).

13 Jejen Musfah, Redesain Pendidikan Guru, Teori Kebijakan Dan Praktik (Kencana Prenadamedia, 2015).

14 Mutahajar, "Penerapan Supervisi Kolaboratif Untuk Meningkatkan Kompetensi Profesional Guru Sdn 6 Jurit Kecamatan Pringgasela." 
Libri Rizka P.W., Supervisi Akademik Internal Guru TK Pendekatan Kolaboratif

ABA Sumberadi supervisor menggunakan pendekatan supervisi kolaboratif.

Pendekatan supervisi kolaboratif merupakan salah satu pendekatan supervisi yang dapat digunakan oleh kepala sekolah selaku supervisi internal secara kolegial, bersifat mendampingi dan kemitraan dalam membimbing/memfasilitasi guru agar dapat melaksanakan tugas profesionalnya. Karakteristik pendekatan supervisi kolaboratif dalam pembimbingan terhadap guru menempatkan kepala sekolah sebagai rekan kerja, kedua belah pihak berbagi kepakaran, diskusi dilaksanankan dengan terbuka dan fleksibel serta memiliki tujuan jelas, membantu guru berkembang menjadi tenaga profesional melalui kegiatan-kegiatan reflektif. ${ }^{15}$

Supervisi dapat dilaksanakan dengan menggunakan pendekatanpendekatan tertentu. Pendekatan kolaboratif merupakan pendekatan yang memadukan cara pendekatan direktif dan non direktif menjadi pendekatan baru. Pada pendekatan kolaboratif ini, supervisor dan yang disupervisi bersama-sama sepakat untuk menetapkan proses dan kriteria dalam melaksanakan percakapan tentang masalah yang dihadapi.

Supervisi dengan pendekatan kolaboratif terjadi dua arah yakni dari atas atau pimpinan ke bawah atau staf dan sebaliknya. Pendekatan kolaboratif dalam supervisi diharapkan dapat memberikan solusi terhadap masalah yang dihadapi guru dengan cepat, karena supervisor dalam mendekati orang yang disupervisi dimulai dengan penciptaan hubungan baik antara keduanya, sehingga dapat diperoleh data yang objektif.

Pendekatan supervisi kolaboratif dalam meningkatkan kompetensi profesional guru untuk mengembangkan materi pembelajaran dilakukan

\footnotetext{
15 Eka Rista Harimurti, "Supervisi Akademik Dalam Upaya Pembinaan Kompetensi Profesional Guru Pendidikan Anak Usia Dini (Paud)," Buah Hati Journal 6, No. 2 (2019): 78-85.
} 
melalui rangkaian kegiatan pembimbingan yang melibatkan seluruh guru yang sedang dibimbing. Dalam melaksanakan supervisi akademik terhadap guru, kepala sekolah hendaknya berpedoman dan menggunakan pendekatan dan teknik supervisi akademik yang tepat. Strategi supervisi kolaboratif yang dijalankan mengantarkannya kepada efektivitas melaksanakan bantuan profesional melalui supervisi akademiknya yang diduga akan meningkatkan kemampuan atau kompetensi profesional guru dalam mengembangkan materi pembelajaran adalah (1) Pembimbingan secara kolaboratif yaitu proses terstruktur dan berkelanjutan antara dua atau lebih pembelajar profesional untuk memungkinkan mereka menanamkan pengetahuan ketrampilan dari sumber-sumber spesialis kedalam praktik sehari-hari. (2) Menempatkan seluruh guru sebagai sentral kegiatan pembimbingan yang mempunyai kedaulatan penuh (3) Urusan supervisi akademik merupakan urusan kepala sekolah sepenuhnya. (4) Diskusi merupakan curah pendapat kondisi awal untuk memperoleh informasi dari guru tentan masalah apa yang sebenarnya sedang dihadapi oleh guru. Pendekatan kolaboratif memiliki karakteristik sebagai berikut : (1) Supervisor bertindak sebagai mitra atau rekan kerja (2) Kedua belah pihak berbagi kepakaran (3) Pendekatan yang digunakan merupakan pendekatan inkuiri (4) Diskusi sebagai langkah lanjut dari pengalaman bersifat terbuka atau felsibel dan tujuannya yang jelas (5) Tujuan supervisi adalah membantu guru dan kepala sekolah berkembang menjadi tenaga-tenaga profesional melalui kegiatan-kegiatan reflektif ${ }^{16}$

\section{TEMUAN DAN PEMBAHASAN}

Berdasarkan hasil penggalian dokumen dan wawancara yang dilakukan oleh kepala sekolah TK ABA sumberadi yaitu ibu Winarni, S. Pd didapatkan data yaitu : TK ABA Sumberadi berdiri sejak tahun 1995,

\footnotetext{
${ }^{16}$ Afrijawidiya Afrijawidiya, Zakaria Zakaria, And Osa Juarsa, "Supervisi Pengajaran Dengan Pendekatan Direktif, Non-Direktif, Dan Kolaboratif," Manajer Pendidikan 11, No. 4 (2017).
} 
Libri Rizka P.W., Supervisi Akademik Internal Guru TK Pendekatan Kolaboratif

gurunya berjumlah 7 orang dengan latar belakang 5 guru pendidikan S1 PAUD, 1 guru pendidikan non PAUD dan satu guru lagi sedang menempuh kuliah di PAUD. Hasil dari penggalian dokumen yang berada pada profil sekolah TK ABA Sumberadi berupa daftar nama guru yaitu :

Tabel 1

Daftar Guru dan Tenaga Kependidikan TK ABA Sumberadi

\begin{tabular}{|c|l|c|c|}
\hline No. & \multicolumn{1}{|c|}{ Nama } & Jabatan & Pendidikan terakhir \\
\hline 1. & Winarni, S. Pd & Kepala Sekolah & S1 PAUD \\
\hline 2. & Ngatinah, S. Pd & Wakil Kepala & S1 PAUD \\
\hline 3. & Sugiyati, S. Pdl & Guru & S1 PAI \\
\hline 4. & Sumadiyono, S. Pd AUD & Guru & S1 PAUD \\
\hline 5. & Rr. Retno Woro. W, S. Pd AUD & Guru & S1 PAUD \\
\hline 6. & Suprapti, S. Sn & Guru & S1 Tari \\
\hline 7. & Afifah Annisa & Guru & SMA \\
\hline
\end{tabular}

Siswanya berjumlah 76 anak terdiri dari 33 TK A dan 43 siswa TK B. Rasio guru dan murid yang dianjurkan oleh Permendikbud 137 tahun 2014 adalah PAUD dengan anak didik berusia 4-6 tahun, yakni untuk jenjang TK maka rasio guru dan anak maksimal 1:15. Artinya satu orang guru sebaiknya tidak melayani lebih dari 15 orang anak didik. Kenyataannya di lembaga TK ABA Sumberadi sudah sesuai dengan permendibud.

Kualifikasi pendidikan guru di TK ABA Sumberadi sudah memenuhi standar kualifikasi pendidik menurut Permendikbud 137 tahun 2014 yakni seorang guru PAUD semestinya berasal dari S1 PAUD. Ada satu guru yang tidak sesuai kualifikasi, namun sudah mengikuiti diklat dasar dan tingkat lanjutan. Dua guru merupakan guru PNS, 5 guru sudah sertifikasi dan 2 guru belum sertifikasi. ${ }^{17}$

Hasil dari wawancara yang dilakukan oleh peneliti kepada kepala sekolah adalah tahapan yang dilakukan kepala sekolah dalam melaksanakan supervisi akademik yaitu melakukan perencanaan. Langkah supervisi akademik dengan pendekatan kolaboratif meliputi: (1) perencanaan yang terdiri dari : melakukan perencanaan awal dengan guru

\footnotetext{
17 Hasil Penggalian Dokumen Profi Tk Dan Ktsp Di Tk Aba Sumberadi Tanggal 3 Desember 2020
} 
tentang permasalahan yang dihadapi guru, melakukan perumusan tujuan supervisi, jadwal supervisi, dan mengembangkan instrumen yang akan dipakai. Pada tahapan perencanaan ini kepala sekolah juga membimbing guru dalam membuat RPP, (2) Pelaksanaan setelah sosialisasi dan kesepakatan dengan guru, pelaksanaan supervisi meliputi memeriksa kelengkapan perangkat pembelajaran. Perangkat pembelajaran yang telah dibuat oleh guru diperiksa dan diberikan penilaian melalui instrumen, mengamati proses pembelajaran yang dilakukan oleh guru melakukan penilaian pembelajaran, dalam hal ini karena pembelajaran yang dilakukan berupa daring melalui google meet karena adanya pandemi covid. (3) analisis hasil supervisi dengan mengidentifikasi kekuatan dan kelemahan guru. Hasil analisis ini dibicarakan dengan guru, lalu dibuat kesimpulan. ${ }^{18}$

Untuk supervisi akademik dengan pendekatan kolaboratif kepala sekolah melakukannya selama dua kali dalam semester atau tiga bulan sekali. Kepala sekolah sudah membuat jadwal yang akan dilaksanakan selama satu tahun ajaran. Hasil wawancara oleh guru tentang tindakan yang dilakukan kepala sekolah dalam supervisi akademik dengan pendekatan kolaboratif :

Tabel 2

Pembahasan Temuan

\begin{tabular}{|c|l|l|}
\hline No. & \multicolumn{1}{|c|}{$\begin{array}{c}\text { Langkah Pendekatan } \\
\text { Kolaboratif }\end{array}$} & \multicolumn{1}{c|}{ Tindakan Kepala Sekolah } \\
\hline 1. & Perencanaan & $\begin{array}{l}\text { Sebelum diadakan supervisi kepala mengumpulkan guru } \\
\text { untuk meeting terlebih dahulu, kemudian di dalam } \\
\text { meeting tersebut kepala sekolah menjelaskan bahwa } \\
\text { akan ada supervisi yang akan dilaksanakan. Pada saat } \\
\text { meeting kepala sekolah menyertakan dokumen } \\
\text { pendukung seperti (1) hasil supervisi akademik yang } \\
\text { sudah dilakukan sebelumna (2) data personel guru TK } \\
\text { yang akan di supervisi (3) administrasi pendukung } \\
\text { pembelajaran seperti rencana pembelajaran, modul } \\
\text { pembelajaran, bahan ahar, absesnsi kehadiran guru TK } \\
\text { dan peserta didik serta hasil penilaian pembelajaran. } \\
\text { Pada saat meeting kepala sekolah juga bertanya kepada } \\
\text { guru kendala apa saja yang dihadapi atau yang muncul } \\
\text { dalam proses pembelajaran selama pandemi covid ini. }\end{array}$ \\
\hline
\end{tabular}
${ }^{18}$ Donni Juni Priansa And Sonny Suntani Setiana, "Manajemen Dan Supervisi Pendidikan,"
Bandung: CV Pustaka Setia, 2018. 


\begin{tabular}{|c|c|c|}
\hline & & $\begin{array}{l}\text { Setelah permasalahan selesai diungkapkan kemudian } \\
\text { kepala sekolah dan guru berdiskusi bersama tentang } \\
\text { tujuan supervisi yang akan dilaksanakan, setelah tujuan } \\
\text { supervisi selesai dibahas kemudian diskusi berkembang } \\
\text { membuat instrumen yang akan digunakan untuk menilai } \\
\text { supervisi. Instrumen supervisi telah selesai maka langkah } \\
\text { selanjutnya adalah membuat jadwal pelaksanaan } \\
\text { supervisi. Pada tahapan perencanaan ini kepala sekolah } \\
\text { juga membimbing guru untuk membuat RPPM yang akan } \\
\text { dibagikan kepada peserta didik pada awal minggu. } \\
\text { Karena pada saat pandemi ini pedoman guru dalam } \\
\text { proses pembelajaran adalah RPPM bukan RPPH. Kepala } \\
\text { sekolah membimbing guru memilih kegiatan apa yang } \\
\text { sesuai untuk BDR (belajar dari rumah), kegiatan yang } \\
\text { dibuat haruslah kegiatan sederhana yang bisa diterapkan } \\
\text { oleh wali murid di sekolah. Alat bahan yang digunakan } \\
\text { juga yang mudah di cari atau sudah tersedia di rumah } \\
\text { pada umumnya. }\end{array}$ \\
\hline 2. & Pelaksanaan & $\begin{array}{l}\text { Pada kegiatan pelaksanaan, kepala sekolah menilai } \\
\text { RPPM yang telah dibuat oleh guru, RPPM penilaian } \\
\text { disesuaikan dengan instrumen yang telah dibuat pada } \\
\text { saat meeting pada tahap perencanaan. Setelah RPPM } \\
\text { dinilai maka kepala sekolah mengamati proses } \\
\text { pembelajaran yang dilakukan oleh guru, pembelajaran } \\
\text { yang dilaksanakan menggunakan google meet. RPPM } \\
\text { dan LKA sudah dibagikan sebelumnya oleh wali murid. } \\
\text { Penilaian proses pembelajaran dilihat dari instrumen } \\
\text { tentang kegiatan guru dalam proses pembelajaran : } \\
\text { Pembukaan (berdoa, apersepsi tema), kegiatan inti } \\
\text { (menggunakan LKA), dan penutup (recalling). Dan yang } \\
\text { terkahir adalah hasil penilaian guru terhadap kegiatan } \\
\text { yang diberikan oleh peserta didik. }\end{array}$ \\
\hline 3. & Analisis hasil supervisi & $\begin{array}{l}\text { Analisis hasil supervisi ini dilakukan untuk melihat } \\
\text { kelemahan dan kelebihan oleh guru. Dari hasil supervisi } \\
\text { tersebut telah mengidentifikasi bahwa kelemahan dari } \\
\text { supervisi ini adalah dari pihak orangtua yang kurang } \\
\text { mendukung proses pembelajaran menggunakan google } \\
\text { meet karena alasan kesibukan pekerjan yang tidak bisa } \\
\text { ditinggalkan, selain itu kelemahan yang kedua adalah } \\
\text { tentang lemahnya sinyal pada saat daring. Untuk } \\
\text { kelebihannya, kemampuan guru mulai berkembang } \\
\text { dalam bidang teknologi dengan menggunakan laptop dan } \\
\text { google meet. }{ }^{19}\end{array}$ \\
\hline
\end{tabular}

Dari hasil supervisi yang dilakukan kemudian kepala sekolah dan guru melakukan diskusi tentang kelemahan yang ditemukan kemudian mencari solusi dari masalah tersebut, dan akan membuat kesimpulan. Setelah itu hasil supervisi akademik akan ditindak lanjuti untuk 
meningkatkan kompetensi guru. Bagi peserta didik hasil yang didapatkan berupa (1) model pembelajaran yang sesuai dengan kebutuhan dan karakteristik peserta didik (2) budaya belajar yang lebih baik (3) suasana pembelajaran yang lebih kondusif.

Peneliti mengamati bahwa pelaksanaan supervisi dengan pendekatan kolaboratif lebih cenderung dilakukan dengan tehnik diskusi antara kepala sekolah dengan guru. Dimulai dari membuat jadwal supervisi, membuat perencanaan untuk proses pembelajaran guru melakukan konsultasi dahulu dengan kepala sekolah. Pada saat pelaksanaan kepala sekolah juga mendampingi guru sehingga setelah kegiatan supervisi guru bisa melihat kekurangan yang dilakukan pada saat melaksanakan proses pembelajaran kemudian kepala sekolah memberikan catatan tindak lanjut untuk perbaikan kedepannya dengan mencari solusi secara bersama-sama.

\section{KESIMPULAN}

Setelah penulis melakukan wawancara dan dokumentasi serta menganalisa data maka penulis dapat mengambil kesimpulan sebagai berikut : Kepala sekolah TK ABA Sumberadi lebih memilih untuk menggunakan pendekatan kolaborasi dalam supervisi yang dilakukan. Para guru lebih tertarik dengan pendekatan kolaborasi yang digunakan dalam supervisi akademik, daripada pendekatan yang lain. Pendekatan kolaborasi dalam supervisi akademik lebih sering dipilih oleh kepala sekolah dalam suatu lembaga karena pendekatan ini dipandang lebih efektif untuk perbaikan di lembaga. Kepala sekolah lebih leluasa menggali masalahmasalah yang muncul dalam proses pembelajaran yang ditemukan oleh guru. Selain itu pendekatan ini lebih menekankan untuk berdiskusi dan mencari solusi dari masalah yang muncul secara bersama-sama. 


\section{DAFTAR PUSTAKA}

Afrijawidiya, Afrijawidiya, Zakaria Zakaria, And Osa Juarsa. "Supervisi Pengajaran Dengan Pendekatan Direktif, Non-Direktif, Dan Kolaboratif." Manajer Pendidikan 11, No. 4 (2017).

Aryani, Nini, M S Mudjiran, And M Pd Rakimahwati. Manajemen Pembelajaran Paud: Berbasis Perkembangan Anak. Edu Publisher, 2020.

Awaluddin Sitorus, M Pd, And Siti Kholipah. Supervisi Pendidikan: Teori Dan Pengaplikasian. Swalova Publishing, 2018.

Harimurti, Eka Rista. "Supervisi Akademik Dalam Upaya Pembinaan Kompetensi Profesional Guru Pendidikan Anak Usia Dini (Paud)." Buah Hati Journal 6, No. 2 (2019): 78-85.

Hermawan, Iwan. Metodologi Penelitian Pendidikan (Kualitatif, Kuantitatif Dan Mixed Method). Hidayatul Quran, 2019.

Kusumawati, Desi. "Supervisi Akademik Kepala Sekolah Terhadap Manajemen Pembelajaran Paud." Satya Widya 32, No. 1 (2016): $41-48$.

Mulyana, Nana. Modul Pengembangan Kemampuan Supervisi Akademik Bagi Kepala Sekolah. Edu Publisher, 2019.

Musfah, Jejen. Redesain Pendidikan Guru, Teori Kebijakan Dan Praktik. Kencana Prenadamedia, 2015.

Mutahajar, Mutahajar. "Penerapan Supervisi Kolaboratif Untuk Meningkatkan Kompetensi Profesional Guru Sdn 6 Jurit Kecamatan Pringgasela." Bintang 1, No. 3 (2019): 282-303.

Nugraha, Mulyawan Safwandy. "Pelaksanaan Supervisi Akademik Oleh Kepala Madrasah Aliyah Swasta Di Kabupaten Sukabumi Jawa Barat." Nadwa 9, No. 1 (2014): 39-68.

Priansa, Donni Juni, And Sonny Suntani Setiana. "Manajemen Dan Supervisi Pendidikan." Bandung: Cv Pustaka Setia, 2018.

Sihite, Hotnida. "Upaya Meningkatkan Kompetensi Profesional Guru 
Melalui Penerapan Pendekatan Supervisi Kolaboratif Bagi Guru Sd Negeri 157019 Pinangsori 12 Kecamatan Pinangsori Kab. Tapanuli Tengah Pada Semester Ganjil Tahun Pelajaran 2019/2020." Peteka 2, No. 2 (2019): 83-94.

Simbolon, Marike. "Penerapan Pendekatan Supervisi Kolaboratif Untuk Meningkatkan Kompetensi Profesional Guru Di Sd Negeri 10 Lumban Suhisuhi Kecamatan Pangururan Kabupaten Samosir." Informasi Dan Teknologi IImiah (Inti) 6, No. 1 (2018): 108-13.

Yusuf, A Muri. Metode Penelitian Kuantitatif, Kualitatif \& Penelitian Gabungan. Prenada Media, 2016. 